\title{
Extraction of Lignin from Empty Fruit Bunch Fiber via Microwave-Assisted Acid Hydrotrope Solvent
}

\author{
N.F. Jafri ${ }^{1},{ }^{*}$, M.N.A. Yaakob ${ }^{1}$, R. Roslan ${ }^{1}$ \\ ${ }^{1}$ Faculty of Manufacturing Engineering, Universiti Malaysia Pahang, 26600 Pahang, Malaysia. \\ ${ }^{2}$ Faculty of Electrical and Electronics Engineering, Universiti Malaysia Pahang, 26600 Pahang, Malaysia. \\ ${ }^{3}$ Faculty of Engineering and Technology, Multimedia University, 75450 Melaka, Malaysia.
}

\begin{abstract}
Lignin is a sub-product from lignocellulose apart from cellulose and hemicellulose that produced from empty fruit bunch fiber (EFB). Lignin has low solubility and reactivity due to its bulky macromolecule structre. Being one of the wastes that being generated in massive amount, many alternatives has been taken to transform lignin into valuable products. To do so, many reactions are needed for the lignin to go through. In this study, lignin will be extracted from empty fruit bunch (EFB) with the aid of acid hydrotrope concentration of $30 \%$ and microwave assisted with various extraction heating time and temperature. Characterization of lignin is done using Fourier Transform Infrared Spectroscopy (FTIR), Thermogravimetric analysis (TGA), Differential Scanning Calorimetry (DSC) and Nuclear magnetic resonance (NMR) while Scanning Electron Microscopy (SEM) and X-ray Powder Diffraction (XRD) used to characterize residues. The highest percentage of lignin yield and its purity obtained are $19.47 \%$ and $96.63 \%$ with the reaction time and temperature of the microwave is 30 minutes and $90{ }^{\circ} \mathrm{C}$. From Fourier Transform Infrared Spectroscopy (FTIR), a wide band at $3430.09 \mathrm{~cm}^{-1}$ and $3413.45 \mathrm{~cm}^{-1}$ are observed due to $\mathrm{O}-\mathrm{H}$ stretching vibration. As for peak at $1123.17 \mathrm{~cm}^{-1}$ and $1051.26 \mathrm{~cm}^{-1}$, it correspond to syringyl and guaicyl unit in both lignin and raw EFB. As for Thermogravimetric analysis (TGA), it shows that lignin decomposes slowly compared to raw EFB due to the aromatic structure of lignin that is very stable, therefore leading to difficulty of decomposing while from Differential Scanning Calorimetry (DSC), after removing cellulose and hemicellulose, glass transition temperature $(\mathrm{Tg})$ obtained from lignin DSC spectroscopy is $193.05^{\circ} \mathrm{C}$ at heat flow of $1.15 \mathrm{~mW} / \mathrm{mg}$. Next, from Nuclear magnetic resonance (NMR) spectroscopy, the signals observed around 6.5-8.0 ppm indicate aromatic $\mathrm{H}$ in syringyl and guaiacyl unit only at lignin spectra while at $3.3-4.0 \mathrm{ppm}$, raw EFB has an intense peak compared to lignin which attribute to methoxyl group. When the residue of the lignin as well as the raw EFB powder is characterized using X-ray Powder Diffraction (XRD), the crystallinity index of the lignin with reaction time and temperature of the microwave 30 minutes and $90{ }^{\circ} \mathrm{C}$ is the highest, $69.28 \%$. As a conclusion, an admissible percent of lignin yield and purity is able to be obtained with addition of acid hydrotrope depending on the variables. From the spectroscopies characterization, it is proved that lignin characteristics and properties are compatible for the production of new and value added products. .
\end{abstract}

ARTICLE HISTORY

Received: $30^{\text {th }}$ July 2021

Revised: 1 Sept 2021

Accepted: $4^{\text {th }}$ Nov 2021

\section{KEYWORDS}

Empty fruit bunch

Lignin

Acid hydrotrope

Microwave assisted

\section{INTRODUCTION}

Biomass sources are abundant, as they can be found almost everywhere on earth. Since empty fruit bunch fiber (EFB) is a type of renewable energy resource, many research and development efforts are put to enhance the expansion of the renewable energy plant in Malaysia and support Malaysia's Small Renewable Energy Power Plant Program at the same time. This program aimed to reduce at least $40 \%$ of greenhouse gas emissions. Examples of renewable energy sources in Malaysia are residues from the forest, oil palm biomass, solar thermal energy, mill residues, municipal solid waste, and sawdust [1]. As a result, massive EFB production and serious disposal problem arise. It is expected that Malaysia will be the world's largest producer and exporter of palm oil in 2020, producing about half of the world palm oil production (10.8 million tonnes) [2]. Therefore, various studies have been done to ensure that this biomass is utilized and converted into high value-added products. In this study, lignin will be focused more due to its massive amount as a by-product in the Malaysian Oil Palm industries. Lignin is acquired and dried from the plant precisely, empty fruit bunch (EFB) formed during the palm oil milling process. It also has high potential application in the pulp and paper industry [3]. Lignin is one of the major components of lignocellulose apart from hemicellulose and cellulose. Lignin drew much recognition from the researcher due to its intransigent behavior in the pulping process, pasture digestibility, and biofuels' processing from biomass. 
Lignin made most of the structural material in wood or biomass. Essentially, it provides rigidity that halts the rapid break down of the cellulosic material. Moreover, it can be found not only between cells but also inside the cells themselves. Lignin is a complex polymer synthesized majorly from three hydroxycinnamyl alcohols: p-coumaryl, coniferyl, and sinapyl alcohols [4]; which when transformed into a polymer, forming p-hydroxyphenyl (H), guaiacyl (G), and syringyl (S) units, randomly linked with aryl ether, ester, or carbon bonds [4]. As lignin has an aromatic structure, it is more chemically stable. Due to this, lignin inherits recalcitrant behavior toward the degradation process [5]. The properties of lignin are determined by its derivatives literally. However, nearly all of the lignin in biomass is insoluble in inert solvents. According to [6], the rate of delignification depends on the content of lignin and the presence of syringylpropane unit hardwood lignin. [7] stated that guaiacyl-lignified fibers were much harder to be pulped compared to syringyl-lignified fibers. During the extraction process, lignin is generally isolated from the biomass into phenolic compounds compared to its native state. However, in polymeric form, lignin has very narrow uses and low reactivity due to steric hindrance. Lignin is often generally viewed as waste with low value. Currently, lignin is primarily burned in a boiler to generate heat and steam. Therefore, to increase the usability of lignin, an advanced extraction method that capable of extracting low molecular weight and further increase its reactivity is necessary.

Various extraction methods have been developed previously, such as dilute acid, alkaline, organosolv, ionic liquid, and sulfite. Recently, recyclable acid hydrotropes (p- $\mathrm{TsOH})$, gain much attention due to their lignin extraction capabilities. Hydrotropy is a solubilization process that when a large amount of second solute is added results in the increment of aqueous solubility of another solute [8]. Hydrotropic acid is a compound comprised of both hydrophilic and hydrophobic functional groups. Hydrotrope has a structure that is almost similar to surfactant. However, the hydrophobic functional group is much shorter. Lignin as phenolic polymer displays hydrophobicity and does not soluble in water, whereas the hydrotrope agent is soluble in water. Therefore, the aqueous hydrotrope solutions will solubilize lignin. The utilization of hydrotropic acid will improve the performance in dissolving lignin at temperatures under the boiling water level [9]. The hydrotrope resolves the hydrophobicity of lignin in water by self-association when the hydrotrope concentration makes to the minimum hydrotrope concentration (MHC). At the minimum hydrotrope concentration, hydrotropes molecules start to aggregate. Exceeding the MHC, the solubility of organic compound increase gradually. Hydrotropy solution does not occur in a linear fashion but with the increase in hydrotrope concentration [8]. Hydrotropic acid such as p-TsOH can depolymerize lignin through ether bond cleavage and isolate carbohydrate-free lignin from the empty fruit bunch (EFB) [10].

The objective of this research is to optimize the extraction of lignin from EFB fiber using acid hydrotrope with microwave-assisted heating. Other than that, to investigate how different temperatures and reaction times of microwave reaction affect the lignin yield and its purity as well as to investigate how acid hydrotrope affects the property of lignin and the residue after the reaction. Based on the objectives, this study's main scope is to extract lignin from EFB using acid hydrotrope as a solvent with microwave-assisted heating. Apart from observing how different temperatures and reaction time play roles in determining the lignin yield and purity. The residues and lignin obtained after extraction are characterized to distinguish the properties between native and technical lignin. The characterization for lignin is done through Fourier Transform Infrared Spectroscopy (FTIR), Thermogravimetric analysis (TGA) and Nuclear magnetic resonance (NMR) and Differential Scanning Calorimetry (DSC). X-ray Powder Diffraction (XRD) is used to observe the crystallinity after reaction with acid hydrotrope.

From the previous study, at a temperature of $80^{\circ} \mathrm{C}$, lignin is isolated with the aid of p-TsOH hydrotrope $(70$ wt \%), DES (ChCl: lactic acid=1:9, mass ratio), and IL ([Amim][Cl]). Results obtained showed that lignin extraction and dissolving hemicellulose by p-TsOH hydrotrope is the highest. Approximately $86 \%$ of lignin and $77 \%$ of hemicellulose can be removed with a $1.5 \mathrm{~h}$ time. After $2.5 \mathrm{~h}$, about $90 \%$ of lignin and $85 \%$ of hemicellulose are isolated. As for the deep eutectic solvent (DES), it displays an average ability to separate lignin with only $11 \%$ after $1.5 \mathrm{~h}$. However, no lignin removal occurs for the treatment with ionic liquid (IL) [10].

\section{MATERIALS AND METHODS}

\section{Materials}

Materials used in this experiment are P-toluenesulfonic acid (p-TsOH) (30 wt \%), EFB fibers (Szetech Sdn Bhd), deionized water and sulfuric acid (95wt \%).

\section{Methodology}

\section{Pre-treatment of EFB fiber}

The EFB fibers are initially ground into a powder with a commercial cutting mill (Retsch SM100). Then, the EFB powder was washed frequently with tap water to get rid of the dust, soil and impurities on the surface of the fibers before dried using an oven for 24 hours under $80^{\circ} \mathrm{C}$. The dried fibers were stored in a dry cabinet for further use. 


\section{Lignin extraction from EFB fiber using microwave-assisted}

In this study, acid hydrotrope was used to extract lignin from EFB. EFB powder and 30 wt.\% of p-TsOH hydrotrope were mixed at a weight ratio of $1: 1$. Then, the mixture was heated at a temperature of $70{ }^{\circ} \mathrm{C}$ and $90{ }^{\circ} \mathrm{C}$ for 10 and 30 minutes, followed by filtration and precipitation. The lignin extraction from EFB was performed using microwaveassisted heating by mixing $20 \mathrm{~g}$ of EFB with $200 \mathrm{~mL}$ acid hydrotrope and reacted in Milestone Flexiwave advanced flexible microwave synthesis platform. The heating temperature elevated to the selected temperature from room temperature, which in this study $70{ }^{\circ} \mathrm{C}$. The reactions were repeated at different temperatures $90{ }^{\circ} \mathrm{C}$ and reaction time $(10$ and 30 minutes) for optimization. After the reaction was completed, a dark brown liquid was obtained. Then, the reacted solution undergoes filtration. At the end of filtration, both residue and black liquor were obtained. Black liquor is then added to hot water for precipitation before being filtered again. Crude lignin that formed was collected. For the last step, the crude lignin was dried in an oven for a duration of 12 hours at $45^{\circ} \mathrm{C}$. These steps were repeated for the other 3 samples.

\section{Percentage of lignin and purity}

Calculation of lignin yielded

The amount of lignin yielded can be calculated using this equation (1):

$$
L(\%)=\frac{m_{\text {isolated }}}{m_{\text {TAPPI }}} \times 100
$$

where $\mathrm{L}$ is the lignin yielded (\%),

$$
\begin{aligned}
& m_{\text {isolated }} \text { is the mass of lignin isolated in microwave-assisted treatment } \\
& m_{\text {TAPPI }} \text { is the mass of lignin calculated using TAPPI method }
\end{aligned}
$$

The purity of lignin obtained after microwave-assisted heating treatment was calculated using TAPPI T222. In short, $0.01 \mathrm{~g}$ of lignin was mixed with $1 \mathrm{~mL}$ of $\mathrm{H}_{2} \mathrm{SO}_{4}(95 \mathrm{wt} . \%)$. The solution was stirred and heated on a hot plate for an hour to observe the lignin solubility. Then, $2.8 \mathrm{~mL}$ deionized water was added before placed in an autoclave to undergo sterilization for 1 hour at the temperature of $121^{\circ} \mathrm{C}$. The solution was filtered to obtain insoluble lignin and soluble lignin. Insoluble lignin and soluble lignin counted as the overall lignin content purity. Insoluble lignin was obtained from the weight of lignin after filtered and dried on a PTFE membrane, while soluble lignin was measured from the UV absorbance at $320 \mathrm{~nm}$.

\section{Characterization of lignin and residue}

Lignin were characterized using Fourier Transform Infrared (FTIR), Thermogravimetric Analysis (TGA), Nuclear Magnetic Resonance (NMR), Differential Scanning Calorimetry (DSC) while residue was characterized using X-ray Diffraction (XRD). Through FTIR, functional group of lignin was observed. Perkin Elmer Spectrum 100 FTIR Spectrometer showed the FTIR absorption data within a spectral range of 1000-4000 $\mathrm{cm}^{-1}$ with a resolution of $4 \mathrm{~cm}^{-1}$. TGA was used to study the thermal decomposition of lignin and raw EFB using the TGA Q500 TA instrument. Approximately $15 \mathrm{mg}$ samples were weighed and heated from 25 to $900{ }^{\circ} \mathrm{C}$ with a heating rate of $10{ }^{\circ} \mathrm{C} / \mathrm{min}$ and nitrogen flow of $40 \mathrm{~mL} / \mathrm{min}$. Bruker Ultra Shield Plus 500MHz was used to support FTIR result. The solvent used for this study is Dimethyl Sulfoxide-d6 (DMSO-d6) and run at room temperature. The Rigaku Miniflex X-Ray Diffractometer provides information on the crystallinity of the residue. 2-theta used for this characterization was $10^{\circ} \leq 2 \Theta \leq 90$. DSC used in this study is NETZSCH DSC 214-Polyma. The main application of DSC is determining the glass transition temperature ( $\mathrm{T}_{\mathrm{g}}$ ). The sample was run with a heating rate of $10^{\circ} \mathrm{C} / \mathrm{min}$ with nitrogen flow. In this research, the temperature taken was from 30 to $250^{\circ} \mathrm{C}$.

\section{RESULT AND DISCUSSION}

\section{Lignin yield and purity}

Referring to table 1 and Figure 1, reaction temperature plays an important role in determining lignin yield followed by reaction time. The concentration of acid hydrotrope used in this research is only 30 wt $\%$ and manages to delignify tolerable amount of lignin, $4.29 \%, 5.73 \%, 9.33 \%$ and $19.47 \%$. Comparing to (Ansari \& Gaikar, 2014), delignification achieved is $85 \%$ with a reaction temperature of $388 \mathrm{~K}$ but the reaction time 240 minutes. Generally, as pTsOH concentration increase, more solubilizing agent to solubilize the lignin from cellulose and hemicellulose. 
In term of purity, as the lignin yield increase, the purity also increase. Percent of purity obtained from soluble and insoluble lignin value. Insoluble lignin for $\mathrm{A}\left(70{ }^{\circ} \mathrm{C} \& 10\right.$ minutes $), \mathrm{B}\left(90^{\circ} \mathrm{C} \& 10\right.$ minutes $), \mathrm{C}\left(70{ }^{\circ} \mathrm{C} \& 30\right.$ minutes $)$ and $\mathrm{D}\left(90{ }^{\circ} \mathrm{C} \& 10\right.$ minutes) are $45.65 \%, 87.33 \%, 73.44 \%$ and $89.31 \%$. Soluble lignin obtained from UV-Vis spectra are $12.33 \%, 5.6 \%, 13.21 \%$ and $7.32 \%$. Acid hydrotrope treated lignin has higher insoluble lignin than soluble lignin.

Table 1 Lignin yield and purity

\begin{tabular}{cccc}
\hline Temperature $\left({ }^{\circ} \mathrm{C}\right)$ & Time $(\min )$ & Lignin yield $(\%)$ & Purity of lignin $(\%)$ \\
\hline \multirow{2}{*}{70} & 10 & 4.29 & 57.98 \\
& 30 & 5.73 & 86.65 \\
\multirow{2}{*}{90} & 10 & 9.33 & 92.93 \\
& 30 & 19.47 & 96.63 \\
\hline
\end{tabular}

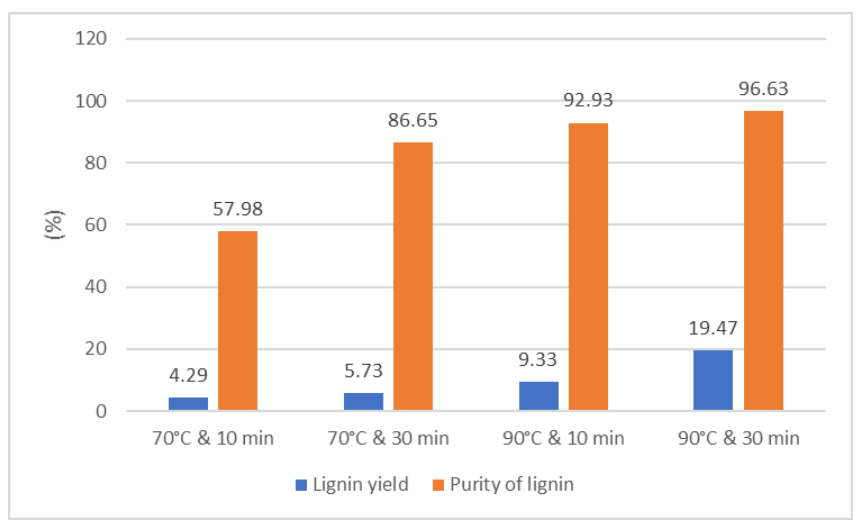

Figure 1 Percentage of yield lignin and purity

\section{X-RAY DIFFRACTION (XRD)}

Sample A is lignin with reaction time and temperature of 10 minutes and $70{ }^{\circ} \mathrm{C}$, sample $\mathrm{B}$ is reaction time and temperature of 10 minutes and $90{ }^{\circ} \mathrm{C}$, sample $\mathrm{C}$ is reaction time and temperature of 30 minutes and $70{ }^{\circ} \mathrm{C}$ and sample $\mathrm{D}$ : reaction time and temperature of 30 minutes and $90{ }^{\circ} \mathrm{C}$.

The crystallinity index of raw empty fruit bunch (EFB) is the lowest among all. Sample D is a residue with the highest lignin yield compared to other samples by means it has the lowest lignin content after delignification. With the increase in temperature and time reaction, the crystallinity index increases from sample A to D. Raw EFB possess a moderate crystallinity index due to cellulose and lignin's presence before reaction. The macromolecules structure of cellulose consists of a hydroxyl group that involves numbers of intra- and intermolecular hydrogen bonds that result in numerous ordered crystalline arrangement structures (Park, Baker, Himmel, Parilla, \& Johnson, 2010). Lignin is an amorphous polymer that has a high molecular weight, therefore, removal of it will lower the amorphous trait (Ghalia \& Dahman, 2017). 


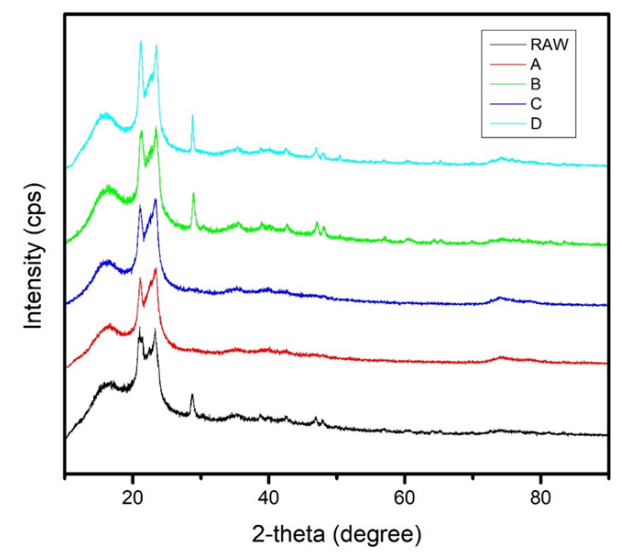

Figure 2 XRD spectra of lignins and raw EFB

Table 2 Crystallinity Index of lignins and raw EFB

\begin{tabular}{cccc}
\hline Sample & $\begin{array}{c}\mathrm{I}_{\mathrm{am}} \\
(\mathrm{cps})\end{array}$ & $\mathrm{I}_{200}(\mathrm{cps})$ & Crystallinity Index $(\%)$ \\
\hline Raw EFB & 776.8 & 1722.14 & \\
A & 642.3 & 1681.1 & 54.89 \\
B & 718.36 & 1959.44 & 61.79 \\
C & 662.85 & 1763.05 & 63.33 \\
D & 761.3 & 2478.39 & 62.4 \\
\hline
\end{tabular}

\section{Thermogravimetric Analysis (TGA)}

There are four stages in the TGA spectroscopy showing types of decomposition. Usually, at stage 1, around the temperature of 30 to $120^{\circ} \mathrm{C}$, the initial weight loss step is attributed to water evaporation. Stage 2 indicates the degradation of carbohydrates into volatile gases, such as $\mathrm{CO}$ and $\mathrm{CO} 2$, at a temperature of 180 to $350{ }^{\circ} \mathrm{C}$. At $350{ }^{\circ} \mathrm{C}$, stage 3 specifies the degradation of previous volatile products, phenolics and alcohol from stage 2 [11]. Above $500{ }^{\circ} \mathrm{C}$, the formation of char lignin and raw EFB. The first decomposition of raw EFB is $5.22 \%$, while lignin is $5.68 \%$ due to the presence of cellulose in raw EFB. The second decomposition of raw EFB is $45.42 \%$, while lignin is $34.89 \%$. The third decomposition of raw EFB is $20.5 \%$, while lignin is $8.86 \%$. Lignin decomposes slowly compared to raw EFB due to the aromatic structure of lignin that is very stable, therefore leading to difficulty decomposing than cellulose or hemicellulose. Higher activation energy needed to decompose biomass with high lignin content [12].

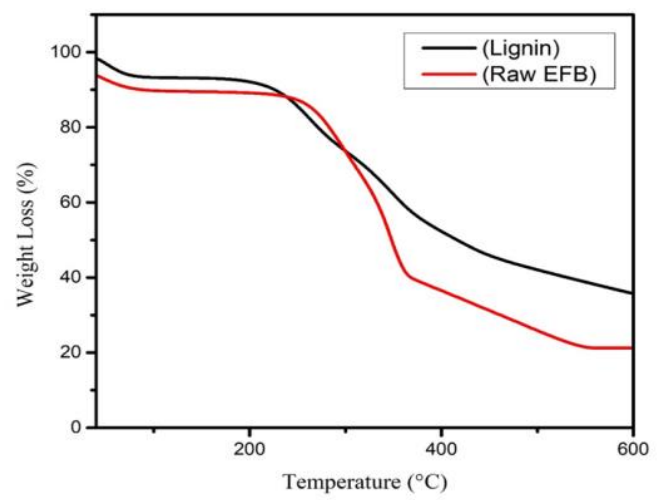

Figure 3 TGA spectra of lignin $\left(90^{\circ} \mathrm{C}\right.$ and 30 minutes $)$ and raw $\mathrm{EFB}$ 
Table 3 Weight decomposition according to stages for lignin and raw EFB

\begin{tabular}{ccc}
\hline Stages & Raw EFB & Lignin \\
\hline \multirow{2}{*}{ Stage1 } & Temperature: $81.82{ }^{\circ} \mathrm{C}$ & Temperature: $79.56{ }^{\circ} \mathrm{C}$ \\
& Weight Loss: $93.78 \%$ & Weight Loss: $93.32 \%$ \\
Stage2 & Temperature: $260.79{ }^{\circ} \mathrm{C}$ & Temperature: $234.63{ }^{\circ} \mathrm{C}$ \\
& Weight Loss: $86.20 \%$ & Weight Loss: $89.78 \%$ \\
Stage3 & Temperature: $364.14{ }^{\circ} \mathrm{C}$ & Temperature: $364.14{ }^{\circ} \mathrm{C}$ \\
& Weight Loss: $40.78 \%$ & Weight Loss: $54.89 \%$ \\
Stage4 & Temperature: $554.86{ }^{\circ} \mathrm{C}$ & Temperature: $446.52{ }^{\circ} \mathrm{C}$ \\
& Weight Loss: $20.28 \%$ & Weight Loss: $46.03 \%$ \\
\hline
\end{tabular}

\section{Fourier Transform Infrared (FTIR)}

Figure 4 shows the FTIR spectra of raw EFB and acid hydrotrope treated lignin at a reaction temperature of $90^{\circ} \mathrm{C}$ and time for 30 minutes. A wide band at $3430.09 \mathrm{~cm}^{-1}$ and $3413.45 \mathrm{~cm}^{-1}$ are originated from $\mathrm{O}-\mathrm{H}$ stretching. The peaks at $1644.47 \mathrm{~cm}^{-1}$ and $1622.50 \mathrm{~cm}^{-1}$ are attributed to the stretching of the $\mathrm{C}=\mathrm{O}$ group. The peaks at $1378.16 \mathrm{~cm}-1$ and $1467.38 \mathrm{~cm}-1$ in both samples are due to bending of C-H bond. Stretching of the C-O group occurs at $1245 \mathrm{~cm}^{-1}$ and $1267.64 \mathrm{~cm}^{-1}$. As for peak at $1123.17 \mathrm{~cm}^{-1}$ and $1051.26 \mathrm{~cm}^{-1}$ correspond to primary alcohol in both lignin and raw EFB. $\mathrm{C}-\mathrm{H}$ stretching can be identified at $2925.43 \mathrm{~cm}^{-1}$ in raw EFB.

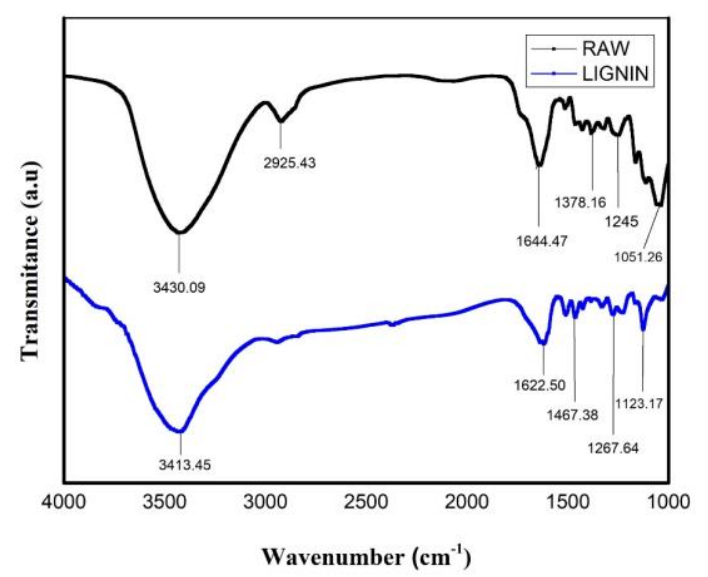

Figure 0 FTIR spectra of lignin $\left(90^{\circ} \mathrm{C}\right.$ and 30 minutes $)$ and raw EFB

\section{Differential Scanning Calorimetry (DSC)}

As for raw EFB, there is no peak due to the presence of lignin, cellulose and hemicellulose. Removing cellulose and hemicellulose, glass transition temperature (Tg) obtained from lignin DSC spectroscopy is $193.05{ }^{\circ} \mathrm{C}$ at heat flow of $1.15 \mathrm{~mW} / \mathrm{mg}$. Apparently, at a temperature below $100{ }^{\circ} \mathrm{C}$, lignin undergoes steep weight loss due to the high evaporation of moisture. This also might be related to the hydroxyl group in lignin bind with many water molecules (Neto et al., 2005). 


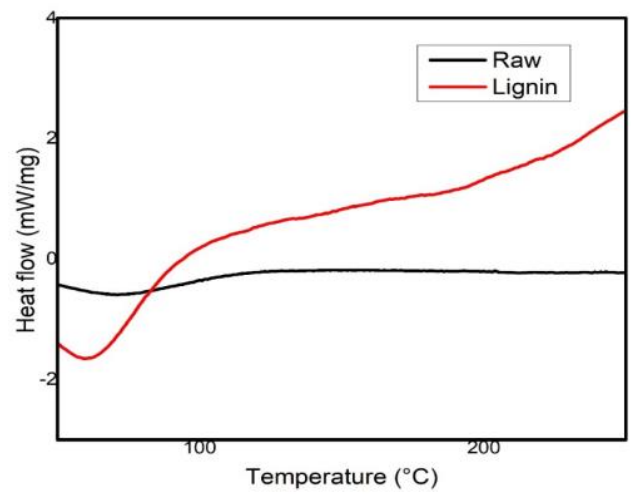

Figure 5 DSC spectra of lignin $\left(90^{\circ} \mathrm{C}\right.$ and 30 minutes $)$ and raw $\mathrm{EFB}$

\section{Nuclear Magnetic Resonance (NMR)}

H NMR has a fast scanning speed for lignin structural identification. From figure 4.6, the top spectra indicate lignin, while at the bottom, the spectra represent raw EFB. The signals observed around (a) $6.5-8.0$ ppm indicate aromatic proton only at lignin spectra. To be exact, the signal at $6.5-6.8 \mathrm{ppm}$ indicates aromatic protons of syringyl unit while at $6.8-7.4 \mathrm{ppm}$ assigned to the aromatic proton of guaiacol unit [13]. Chemical shifts around (b) $3.3-4.0 \mathrm{ppm}$ attribute to water peak due to presence of water.
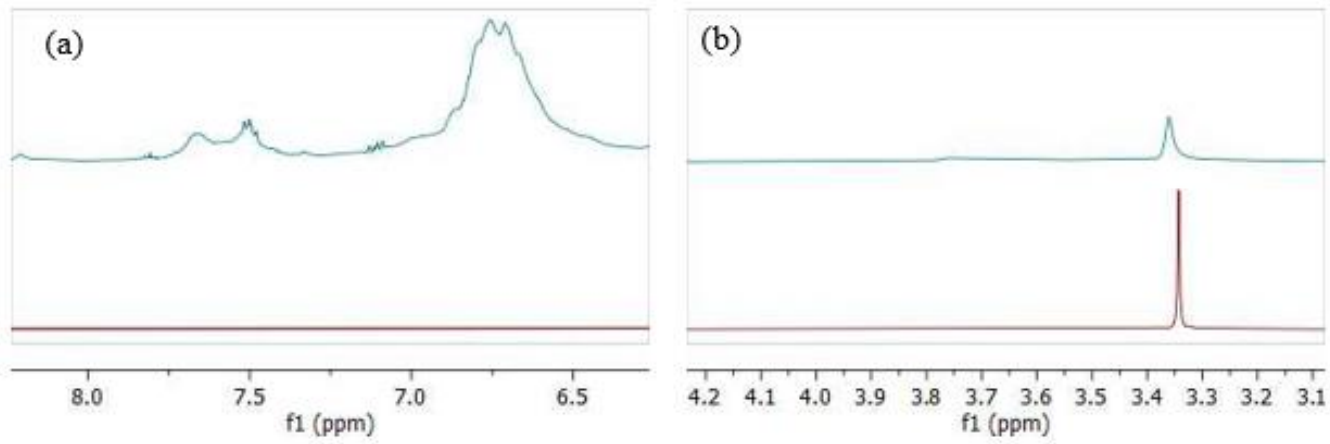

Figure $6 \mathrm{H}$ NMR spectra of raw EFB fibre and lignin $\left(90^{\circ} \mathrm{C}\right.$ and 30 minutes)

Table 6 Signal assignments of H NMR for raw EFB and lignin

\begin{tabular}{cc}
\hline Chemical shift $(\mathrm{ppm})$ & Assignments \\
\hline $6.5-8.0$ & Aromatic H \\
$3.3-4.0$ & Methoxyl \\
\hline
\end{tabular}

\section{CONCLUSION}

Acid hydrotrope is considered an excellent solubilizing agent to delignify lignin from cellulose and hemicellulose. At low concentration, reaction time and temperature, $\mathrm{p}$ - $\mathrm{TsOH}$ assisted in microwave heating able to extract a tolerable amount of lignin. Apart from that, lignin purity of the highest lignin yield $(19.47 \%)$ can also be considered high at $96.63 \%$. From XRD, it is proof that the filtered residue from the highest temperature and time $\left(90{ }^{\circ} \mathrm{C} \& 30\right.$ minutes) lignin has the highest crystallinity index, $69.28 \%$, compared to the raw EFB, 54.89\%. For FTIR, lignin shows typical peaks for lignin structure. Through TGA, lignin shows a slow decomposition rate compared to raw EFB due to its stable structure. As for DSC, transition glass, Tg in lignin, occur at temperature $183.05^{\circ} \mathrm{C}$. 


\section{ACKNOWLEDGEMENT}

The authors are grateful to the Universiti Malaysia Pahang for financial support via internal grant RDU190330. The authors also would like to acknowledge the Faculty of Industrial Science and Technology for its Postgraduate Research Grant Scheme (PGRS1903195).

\section{REFERENCES}

[1] Shahlan, S.S., et al., Process Development of Oil Palm Empty Fruit Bunch Gasification by using Fluidised Bed Reactor for Hydrogen Gas Production. Chemical Engineering Transactions, 2018. 63: p. 559-564.

[2] Abdullah, N. and F. Sulaiman, The oil palm wastes in Malaysia. Biomass now-sustainable growth and use, 2013. 1(3): p. 7593.

[3] Bajpai, P., Application of enzymes in the pulp and paper industry. Biotechnology progress, 1999. 15(2): p. 147-157.

[4] Rencoret, J., et al., Lignin composition and structure in young versus adult Eucalyptus globulus plants. Plant Physiology, 2011. 155(2): p. 667-682.

[5] Ganewatta, M.S., H.N. Lokupitiya, and C. Tang, Lignin biopolymers in the age of controlled polymerization. Polymers, 2019. 11(7): p. 1176.

[6] Tsutsumi, Y., et al., The difference of reactivity between syringyl lignin and guaiacyl lignin in alkaline systems. 1995, Walter de Gruyter, Berlin/New York.

[7] Fergus, B. and D. Goring, Topochemistry of delignification in Kraft and neutral sulphite pulping of birch wood. Pulp Pap Mag Can, 1969.

[8] Kumar, V.S., C. Raja, and C. Jayakumar, A review on solubility enhancement using hydrotropic phenomena. Int. J. Pharm. Pharm. Sci, 2014. 6(6): p. 1-7.

[9] Wu, X., et al., Sequential extraction of hemicelluloses and lignin for wood fractionation using acid hydrotrope at mild conditions. Industrial Crops and Products, 2020. 145: p. 112086.

[10] Ji, H. and P. Lv, Mechanistic insights into the lignin dissolution behaviors of a recyclable acid hydrotrope, deep eutectic solvent (DES), and ionic liquid (IL). Green Chemistry, 2020. 22(4): p. 1378-1387.

[11] Watkins, D., et al., Extraction and characterization of lignin from different biomass resources. Journal of Materials Research and Technology, 2015. 4(1): p. 26-32.

[12] Burhenne, L., et al., The effect of the biomass components lignin, cellulose and hemicellulose on TGA and fixed bed pyrolysis. Journal of Analytical and Applied Pyrolysis, 2013. 101: p. 177-184.

[13] Guo, G., et al., Separation and characterization of lignin from bio-ethanol production residue. Bioresource technology, 2013. 135: p. 738-741. 